\title{
Stress inhibits tryptophan hydroxylase expression in a rat model of depression
}

\author{
Yi Chen ${ }^{1,2, *}$, Haixia Xu' ${ }^{1,2, *}$, Mingyue Zhu ${ }^{1,2}$, Kun Liu ${ }^{1,2}$, Bo Lin ${ }^{1,2}$, Ruxian Luo ${ }^{3}$, Chuanbai \\ Chen ${ }^{3}$ and Mengsen $\mathbf{L i}^{1,2}$ \\ ${ }^{1}$ Key Laboratory of Molecular Biology, Hainan Medical College, Haikou 571199, Hainan Province, P. R. China \\ ${ }^{2}$ Hainan Provincial Key Laboratory of Carcinogenesis and Intervention, Hainan Medical College, Haikou 571199, Hainan \\ Province, P. R. China \\ ${ }^{3}$ Department of Psychiatry, Hainan Provincial Anning Hospital, Haikou 571199, Hainan Province, P. R. China \\ *These authors have contributed equally to this work and are co-first authors \\ Correspondence to: Mengsen Li, email: mengsenli@163.com \\ Chuanbai Chen, email: 812450325@qq.com
}

Keywords: depressive model, tryptophan hydroxylase, epigenetics

Received: March 14, $2017 \quad$ Accepted:May 21, $2017 \quad$ Published: June 28, 2017

Copyright: Chen et al. This is an open-access article distributed under the terms of the Creative Commons Attribution License 3.0 (CC BY 3.0), which permits unrestricted use, distribution, and reproduction in any medium, provided the original author and source are credited.

\section{ABSTRACT}

Serotonin (5-hydroxytryptamine, 5-HT) dysfunction is associated with the pathophysiology of depression. Tryptophan hydroxylase (TPH), the rate-limiting enzyme in 5-HT biosynthesis, is believed to have essential role in many mental disorders, including depression. In the present study, we generated a rat model of depression by exposing the animals to stress, and the rats were then treated with paroxetine. The results indicated that the concentration of 5-HT in the brain and liver tissues were significantly lower in the rat model of depression than in healthy or treated rats. Immunohistochemical analyses of TPH1/2 showed less TPH1 and TPH2 expression, specifically TPH2, in the brain, liver and kidney of the depressive rats than in the healthy rats; In addition, the two TPH isoforms, TPH1 and TPH2, had different spatial distributions, the mRNAs of the TPH1/ 2 genes were significantly decreased and TPH1/ 2 were highly methylated in the depressive model rat, but treatment with paroxetine ameliorated the expression and methylation of TPH1/2. All together, stress was able to inhibit expression of TPH1/ 2 in brain tissue and decrease concentration of 5-HT, the mechanism maybe involve in increasing the methylation of TPH2 genes promoter; Paroxetine has a role in confronting the effect of stress in depressive rat model.

\section{INTRODUCTION}

Depression is a heritable neuropsychiatric syndrome with a high mortality. Although it is a severe and recurrent psychiatric disorder that affects approximately $10 \%$ of people during their lifetime [1,2], the aetiology of depression is still undefined. The current concept of psychiatric disorders posits that both an individual physiological characteristics (e.g., neurotransmitters and neuroendocrine alterations, and genetics) and environmental factors (e.g., society and family) contribute to depression. Although most serotonin (5-HT), one of the best-known neurotransmitters, is distributed peripherally, and 5-HT levels and signalling have been shown to regulate bone mass in mice and humans [3], 2\% of this neurotransmitter is present in the central nervous system and is associated with temperature regulation, circadian rhythmicity, vomiting, aggression, and energy balance $[4,5]$. Dysfunction in 5-HT is associated with the pathophysiology of depression [6-10], and the 5-HT system is a common target of antidepressants.

Biosynthesis of 5-HT is a two-step process; the first and rate-limiting step is conversion of the amino acid L-tryptophan into 5-hydroxytryptophan (5-HTP), which 
is catalyzed by tryptophan hydroxylase (TPH). Two $\mathrm{TPH}$ isoforms (TPH1 and TPH2) have been identified and share $71 \%$ homology in their protein sequence; The protein sequences of TPH1 and TPH2 differ at their N-terminal [11] and exhibit different spatial distribution patterns [12]. TPH1 is primarily located in a variety of non-neuronal cells, such as the enterochromaffin cells of the gut and the pineal gland [13-16], whereas TPH2 is predominantly expressed in the myenteric plexus [17] and in the serotonergic neurons of the raphe nuclei. $\mathrm{TPH}$ acts as the rate-limiting enzyme in 5-HT synthesis [14-16, 18-20]. No substantial overlap has been reported between the expression of the TPH1 and TPH 2 proteins in adults $[20,21]$, supporting the hypothesis that TPH1 primarily catalyzes the synthesis of peripheral 5-HT, whereas TPH2 functions primarily at central serotonergic neurons.

The location and function of TPH2 has made it an essential candidate gene in many mental disorders, including depression. Currently, the majority of research on TPH2 has focused on gene polymorphisms. However, a few studies have examined which TPH 2 gene variant is tightly associated with the aetiology of depression [22]. According to several researchers, epigenetic modification of the TPH2 gene may contribute to modulation in the expression of TPH 2 in central neurons, but confirmatory evidence is lacking. In the present study, we hypothesize that TPH2 regulates the expression of 5-HT by epigenetically modulating the $\mathrm{TPH} 2$ gene. In the process of the metabolism and excretion of antidepressive drug, paroxetine and 5-HT are executed by liver and kidney, and the expression of TPH $1 / 2$ in these tissues influence 5-HT level. We examined the levels of 5-HT, the expression of TPH protein and mRNA, their immunohistochemical localization, and TPH methylation to assess this hypothesis and determine whether 1) TPH1/2 expression was associated with depression and 2) the level of the TPH1/2 proteins showed the same trend as that of mRNAs transcription from the TPH1/2 gene.

\section{RESULTS}

\section{Stress inhibited 5-HT production in various rat tissues}

A comparison of 5-HT concentrations in healthy, depressive, and treated rats was performed using ELISAs. Less 5-HT was observed in brain and liver of the depressive model rat than the healthy and treated rats, but the 5-HT concentrations were significantly increased ( $P<0.05$ compared with the depressive model group) following treatment with paroxetine (Figure 1A, 1B). Additionally, stress may also inhibit production of 5-HT in the kidney of depressive model rats (Figure 1C). These results for the 5-HT level in our experiments were consistent with the neurotransmitter theory of depression, which proposes that 5-HT synthesis is decreased in the brains of patients with depression [23-26]. However, paroxetine treatment could partially restored 5-HT production in the brain and liver tissues.

\section{Stress inhibited TPH1/2 expression in various rat tissues}

To investigate the expression of TPH in distinct tissues of the healthy, depressive, and treated rats, immunohistochemistry and Western blot analyses were performed sequentially. Immunohistochemistry results indicated that the expression of TPH1 was significantly lower in brain, liver and kidney tissues of the depressive model rat than in the healthy and treated rats (Figure 2A). The expression of TPH2 was significantly lower in the brain tissues of the depressive model rat than in the healthy and treated rats, but fewer changes were observed in the liver and kidney tissues from these groups (Figure 2B). Based on the Western blotting results, TPH1 and TPH2 were expressed at significantly lower level in the brain tissues of the depressive model group than in the healthy or treated rats (Figure 3A). Unexpectedly, TPH 2 expression showed little change in the liver and kidney tissues of these groups, but TPH1 expression was not changed in the depressive model group compared to the healthy group. However, TPH1 was expressed at significantly lower levels in the liver and kidney tissues from the treated group compared to the healthy and depressive model groups (Figure 3B, 3C). Thus, stress principally inhibited 5-HT biosynthesis by suppressing TPH2 expression in the brain.

\section{Stress inhibited the expression of TPH1/ 2mRNAs in rat brain tissues}

In the present study, we used RT-PCR analyses to detect the levels of the TPH1/2 mRNAs in the brain, liver and kidney tissues of the experimental rats and to explore the effects of stress on TPH1/2 expression. According to the RT-PCR results, the levels of both the TPH1 and TPH2 mRNAs were significantly lower in the brain tissues of the depressive model group than in the healthy or treated group, and the levels of TPH1 mRNA in the liver and kidney tissues of the depressive model group were not significantly changed compared to the healthy group. However, the expression of TPH1 mRNA was expressed at significantly lower levels in the liver and kidney tissues of the treated group than in the healthy group and depressive model group. The level of the TPH2 mRNA in the liver and kidneys tissue was not significantly changed in these experimental groups (Figure 4A, 4B). Based on these results, stress predominantly inhibited TPH $1 / 2$ expression in the brain. 

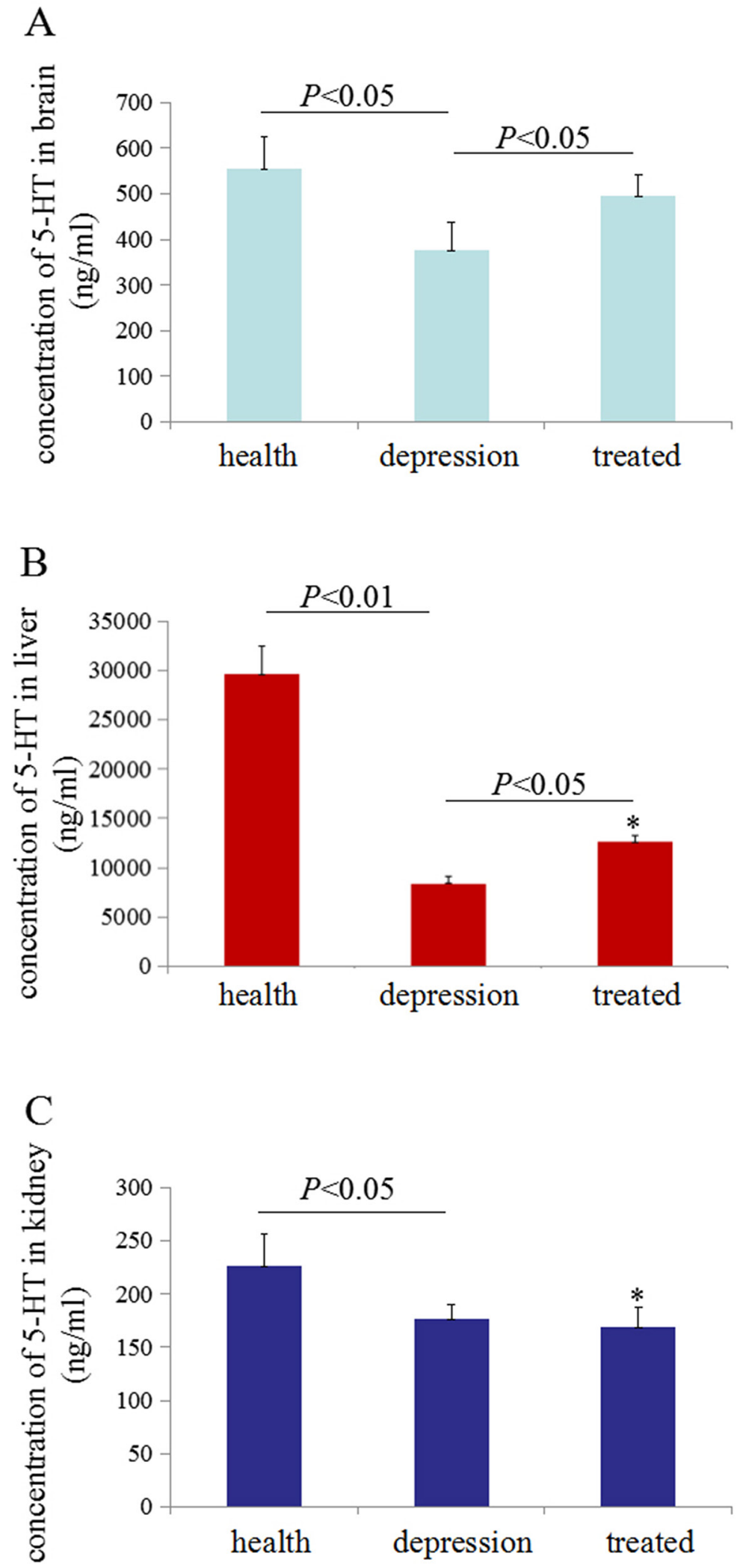

Figure 1: Serotonin (5-HT) concentrations in rat tissues. Enzyme-linked immunosorbent assays (ELISAs) were used to detect 5 -HT concentration in rat tissues. The 5-HT concentrations were measured in $100 \mu \mathrm{g}$ of total proteins extracted from the brain (A), liver (B) and kidney $(\mathbf{C})$ of the rats. ${ }^{*} P<0.05$ vs healthy group. $\mathrm{N}=6$. 


\section{Stress promoted methylation of the $\mathrm{TPH} 1 / 2$ gene in rat brains}

In the present study, we used the un-MSP and MSP methods to analyze the promoters of the TPH1/2 genes and determine whether stress inhibited the expression of the TPH1/2 genes. One $\mathrm{CpG}$ island of theTPH1 gene was identified upstream of bases -177 to -31 with a size of $147 \mathrm{bp}$, and one $\mathrm{CpG}$ island of the TPH2 gene was identified upstream of bases -1983 to -1861 with a size of $123 \mathrm{bp}$. Based on the results from the un-MSP assay the TPH1/2 genes were expressed at significantly lower levels in the brains of the depressive model group than in the healthy or treated group. The results of the MSP-PCR assay, indicated that the TPH2 gene in the brain of the depressive model group was methylated to a significantly higher than in the healthy or treated group(MSP/un-MSP) (Figure 5A-5C). Unexpectedly, the level of methylation of the TPH1 gene was significantly reduced in the liver of the depressive model group compared with the healthy or treated group, but in kidney tissues, the level of methylation of the TPH1 gene was significantly reduced in the depressive model and treated groups than in the healthy group (Figure 5A, 5B). However, the methylation status of the TPH2 gene was not altered in the liver and kidney tissues from the experimental groups (Figure 5A, 5C). Thus, stress inhibited the expression of the TPH2 gene, possibly by promoting the methylation of these genes in the brain.

\section{DISCUSSION}

Decreased expression of 5-HT in the central nervous system has been reported in patients with major depressive disorders, affective disorders, anxiety disorders, and other mood disorders [27, 28]. The concentration of 5-HT is associated with the development of depression disorder, and many reports have shown that tissue or serum 5-HT levels are low in patients with depression [29-31]. Inhibition of 5-HT reuptake also plays an important role in promoting depressive disorders [32]. Thus, the synthesis, transportation, and reuptake of 5-HT are pivotal factors that influence depressive-like behaviours. In the present study, we found that the tissue 5-HT concentrations were significantly decreased in the brain and liver tissues from rats in the stress-induced depressive model than in healthy rats, indicating the successful establishment of the depressive model. The 5-HT levels decreased in depression group and increased in treated rats. However, neither TPH1 nor TPH2 were correlated with the changes observed in the liver and kidney. We think the stress factors may primarily influence the expression of the TPH1 and TPH2 genes in brain tissues, TPH1 and TPH2 in the brain effect 5-HT biosynthesis, 5-HT accumulates in the liver and kidney tissues through the blood circulation. Paroxetine (Paxil) is an antidepressant drug that is used to treat major depressive disorder. The underlying mechanism of paroxetine has recently been shown to involve the inhibition of the activity of the 5-HT transporter, leading to the inhibition of 5-HT reuptake [33, 34], but researchers have not clearly determined whether paroxetine influences the expression of the rate-limiting enzymes in 5-HT synthesis, TPH1/2.

In the present study, stress could significantly inhibit TPH1/2 expression in the brain tissues of rats in the depressive model group in the immunohistochemistry assay, and the paroxetine treatment rescued TPH1/2 expression. We also found that TPH1/2 was expressed in the cytoplasm (Figure 2). Based on these results, paroxetine stimulates the expression of $T P H 1 / 2$ genes.
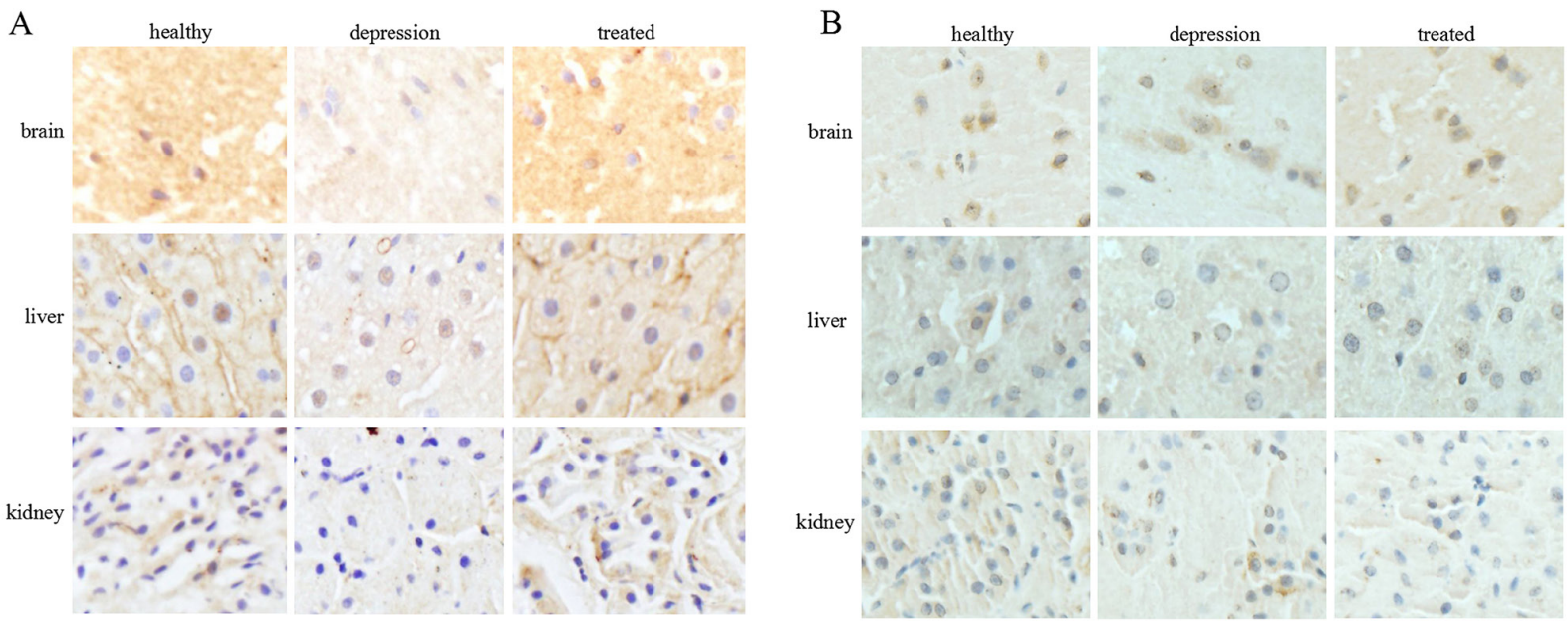

Figure 2: Expression and localization of TPH1/2 in rat tissues. The expression and localization of TPH1 (A) and TPH2 (B) were analyzed by immunohistochemistry in the rat brain, liver, and kidney of the healthy, depressive model, and treated groups. The images are representative of six independent experiments. 
A
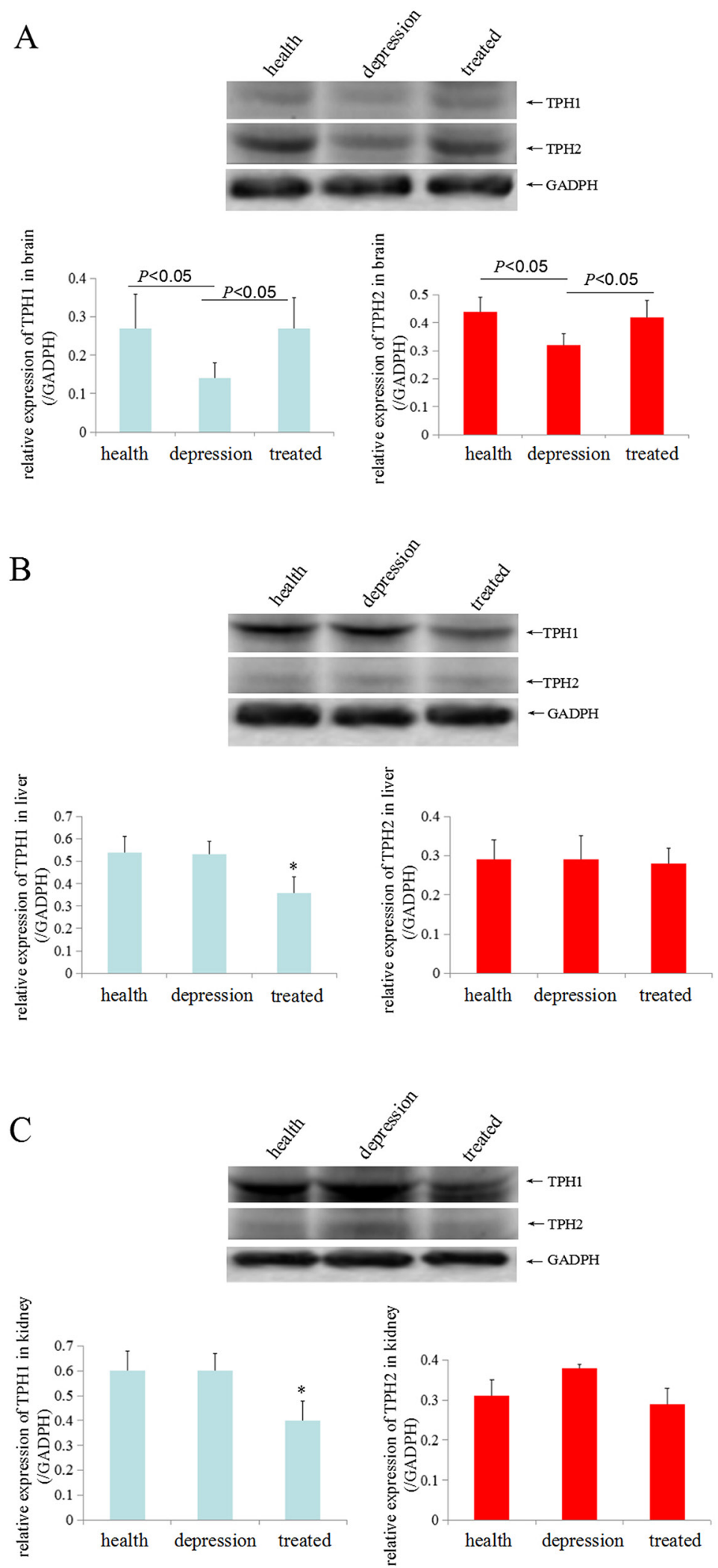

Figure 3: TPH1/2 expression in rat tissues. TPH1/2 expression in the brain (A), liver (B) and kidney tissues (C) from the healthy, depressive model and treated rats was detected by Western blotting. GAPDH (glyceraldehyde-3-phosphate dehydrogenase, a housekeeping gene that is stably expressed in all tissues) was used as an internal control. The images are representative of six independent experiments. $* P<0.05$ vs healthy and depressive model groups. 
Unexpectedly, stress did not inhibit the expression of the TPH1/2 genes in the liver or kidney tissues, but after treatment with paroxetine the inhibition of stress in the expression of TPH2 genes in brain were restored. Paroxetine is an antidepressant in a group of drugs called selective serotonin reuptake inhibitors (SSRIs), SSRIs block serotonin reuptake and increase serotonin stimulation of somatodendritic 5-HT1A and terminal autoreceptors. Because 5-HT biosynthesis is limited by $\mathrm{TPH} 1 / 2$, we explored the effect of paroxetine on TPH1/2 expression in liver and kidney tissues in the present study. After treatment with paroxetine, the TPH1 expression was significantly reduced in the liver and kidney tissues of the treated group than in the healthy or depressive model groups. Paroxetine did not affect TPH2 expression in these tissues (Figure 3). Based on these results, paroxetine selectively regulates TPH1/2 expression in different tissues, indicating a tissue-specific function of paroxetine. This study identified a novel mechanism by which paroxetine treats depressive disorder.

Epigenetic modulation of genes, such as DNA methylation and histone acetylation, affects the transcription of genetic information [35]. An increase in methylation within the promoter of a gene or an increase in histone acetylation leads to gene silencing in most cases [35-37]. We performed RT-PCR and MSPPCR to detect the expression of the TPH1/2 genes and the methylation status of TPH1/2 gene promoters and to explore the mechanism by which stress inhibited the expression of the TPH1/2 genes. The results showed that the expression of TPH1/2 gene mRNAs in the brain tissues of the depressive model group was significantly decreased compared with the healthy or treated group. No changes in the expression of the TPH1 mRNA were detected in the liver and kidney tissues of the depressive model group compared to the healthy group, but treatment with paroxetine significantly reduced the expression of this mRNA in these tissues compared to the depressive model group and the healthy group. The expression of the TPH2 mRNA was not changed in the liver and kidney tissues of these experimental groups (Figure 4). Thus, stress predominantly inhibited TPH1/2 mRNA expression in brain tissues. The MSP results also indicated that the TPH2 gene promoter was methylated to a significantly greater extent in brain tissues from the depressive model group compared to the healthy or treated group. The methylation level of the TPH1 gene promoter was significantly lower in the liver tissue from the depressive model than in the healthy or treated group. However, in kidney tissues, the depressive model group showed no changes compared to the treated group, although methylation was significantly lower in these groups than the healthy group. The methylation status of the TPH2 gene promoter was not changed in liver and kidney tissues from these experimental groups (Figure 5). According to the results of the MSP assay, the decrease in
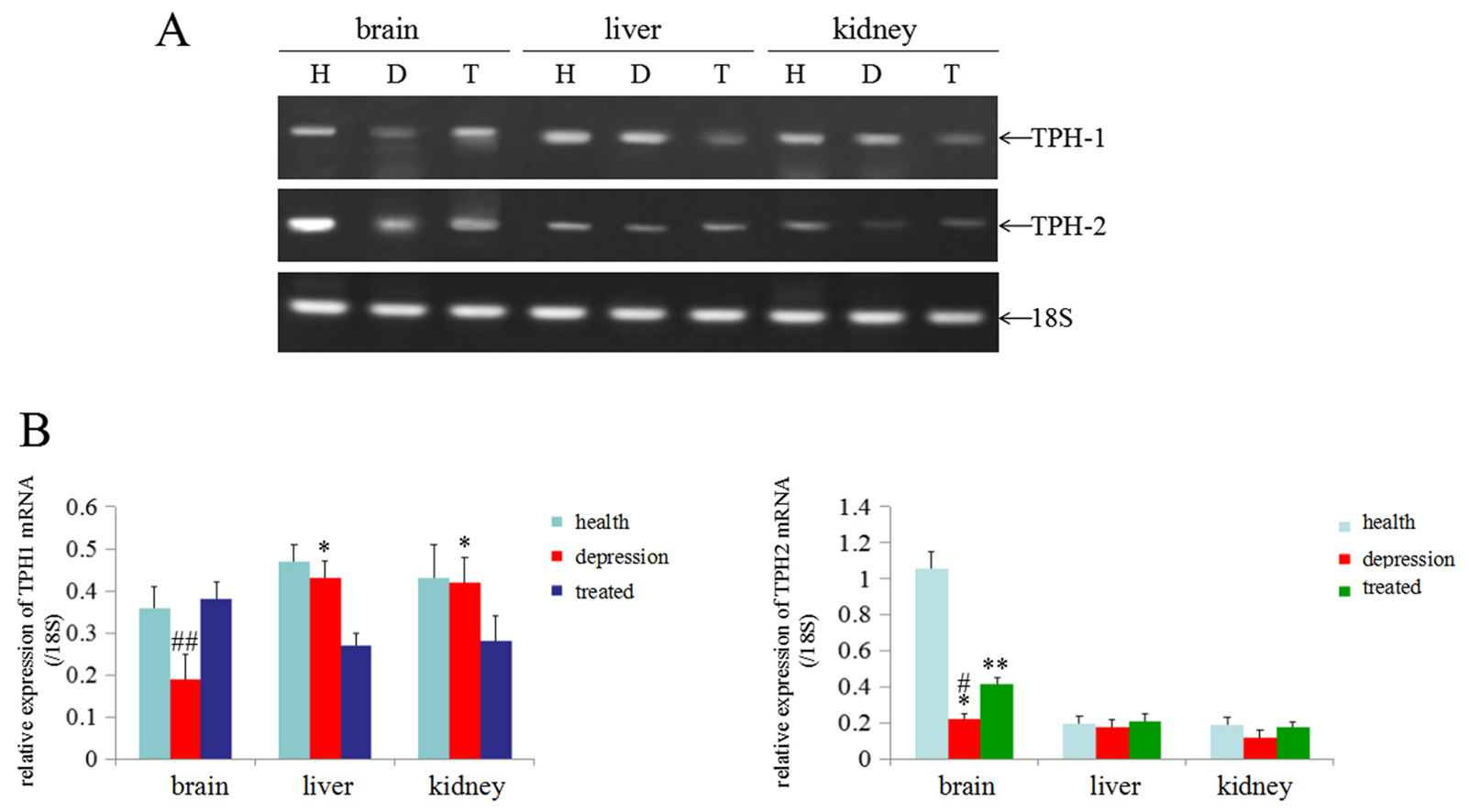

Figure 4: Expression of the TPH1/2 mRNAs in rat tissues. (A) RT-PCR analyses were used to measure the expression of the TPH1/2 mRNAs in the brain, liver and kidney of healthy, depressive modeland treated rats; 18S was used as an internal control. (B) The relative quantity of TPH1/2 mRNAs from RT-PCR (from the images shown in A), ${ }^{\#} P<0.01$ vs healthy and treated groups, ${ }^{*} P<0.05$ vs treated group, ${ }^{* *} P<0.01$ vs healthy group, ${ }^{\#} P<0.01$ vs healthy group. H: Healthy rats; D: depressive model rats; T: depressive model rats treated with paroxetine. The images are representative of six independent experiments. 
TPH2 expression in the rats in the depressive model group may due to an increase in the methylation of the TPH2 gene in brain tissues, consistent with the general function of DNA methylation. To our surprise, the MSP results indicated that the higher levels of methylation of TPH2 gene promoter in rats in the depressive model group, and THP2 expression negatively correlated, but a negative correlation between TPH1 methylation and expression was not observed. The reason may involve the specific expression of TPH1/2 in these tissues, and the observation that stress induced the differential methylation of the TPH2 gene promoter in brain, liver and kidney tissues. We speculate that stress primarily induced changes in the methylation of the TPH2 gene promoter in brain tissue, but mainly induced changes in the methylation of the TPH1 gene promoter in liver and kidney tissues. Moreover

A

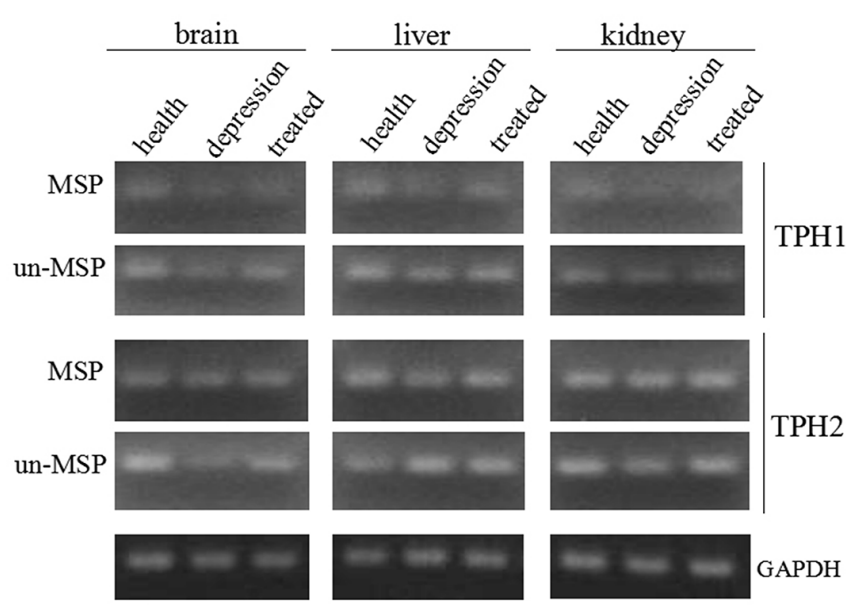

$\mathrm{B}$
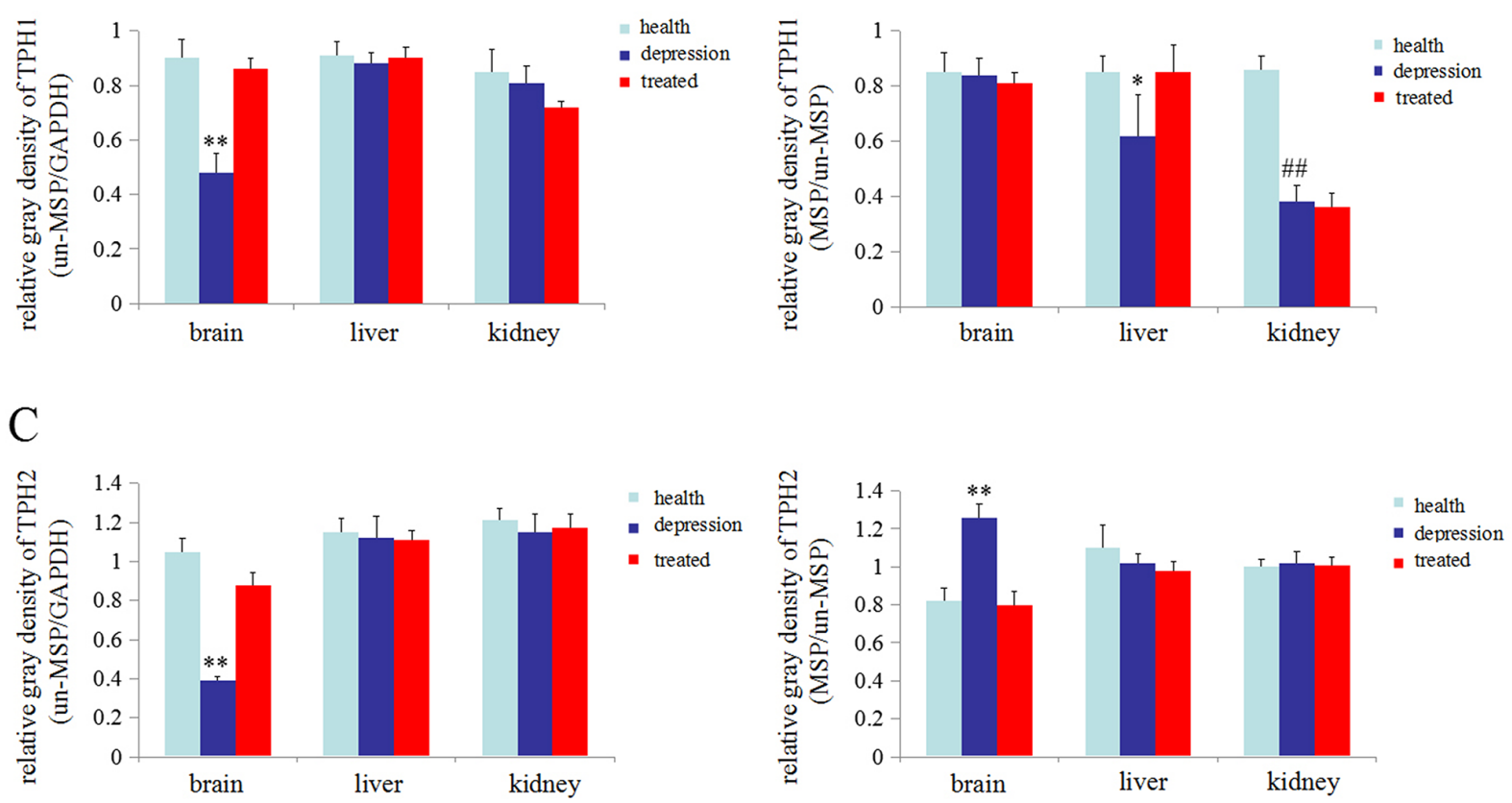

Figure 5: Methylation status of the TPH1/2 genes in rats. (A) Methylation-specific polymerase chain reaction (MSP) was used to assess the methylation status of the TPH1/2 genes in the brain, liver, and kidney of healthy, depressive model and treated rats; GAPDH was used as an internal control. Relativequantity of TPH1 (from the images shown in A) (B) and TPH2 (from the images shown in A) (C) Un-MSP: un-methylated-specificPCR, MSP: methylated-specificPCR. $* * P<0.01$ vs healthy and treated groups, ${ }^{\#} P<0.01$ vs healthy groups. The images are representative of six independent experiments. 
Table 1: Primers for RT-PCR

\begin{tabular}{lcc}
\hline mRNA (accession number) & Primer sequence & Product length (bp) \\
\hline 18s rRNA & 5'-CCTGCGGCTTAATTTGACTC-3' (sense) & 118 \\
(M11188) & 5'-AACTAAGAACGGCCATGCAC-3' (antisense) & 427 \\
TPH1 & 5'-GCTGAACAAACTCTACCCAACCCAC-3' (sense) & 449 \\
(NM_001100634) & 5'-TCGGCACAGTCCAAACTCCACA-3' (antisense) & \\
TPH2 & 5'-AATCTTCGTGGACTGTGAATGTG-3' (sense) & \\
(NM_173839) & 5'-CGTTGTCTTCCCTGTAGCCG-3' (antisense) & \\
\hline
\end{tabular}

Table 2: Primers for MSP

\begin{tabular}{|c|c|c|c|}
\hline Gene & & Primer sequence & $\begin{array}{l}\text { Product length } \\
\text { (bp) }\end{array}$ \\
\hline \multirow[t]{2}{*}{ ТPH1 } & $\begin{array}{l}\text { Methylation- specific } \\
\text { primers }\end{array}$ & $\begin{array}{l}\text { 5'-AATTAAAATTTTACGAGAATAGTTGTG-3' (sense) } \\
\text { 5'-AACGCAAAAAAAAACAACTAATAA -3' (antisense) }\end{array}$ & 154 \\
\hline & $\begin{array}{l}\text { Non-methylation- } \\
\text { specific primers }\end{array}$ & $\begin{array}{c}\text { 5'-TAATTAAAATTTTATGAGAATAGTTGTG -3' (sense) } \\
\text { 5'-CACAAAAAAAAACAACTAATAAAAA -3' (antisense) }\end{array}$ & 153 \\
\hline \multirow[t]{2}{*}{ TPH2 } & $\begin{array}{l}\text { Methylation- specific } \\
\text { primers }\end{array}$ & $\begin{array}{c}\text { 5'-GTGTTTGTAGTATTGATTATTTCGTG -3' (sense) } \\
\text { 5'-TAAAAAAATCAAATTATACGATAACC -3' (antisense) }\end{array}$ & 103 \\
\hline & $\begin{array}{l}\text { Non-methylation- } \\
\text { specific primers }\end{array}$ & $\begin{array}{c}\text { 5'-AGTGTTTGTAGTATTGATTATTTTGTG -3' (sense) } \\
\text { 5'-ACTAAAAAAATCAAATTATACAATAACC -3' } \\
\text { (antisense) }\end{array}$ & 106 \\
\hline$G A P D H$ & & $\begin{array}{c}\text { 5'-GACATGCCGCCTGGAGAAAC-3' (sense) } \\
\text { 5'-AGCCCAGGATGCCCTTTAGT-3' (antisense) }\end{array}$ & 92 \\
\hline
\end{tabular}

paroxetine promoted $T P H 2$ expression by inhibiting the methylation of the TPH2 gene promoter in brain tissues, leading to increase 5-HT synthesis.

\section{MATERIALS AND METHODS}

\section{Animals and generation of the depressive model}

For each group,thirty Sprague Dawley rats (180$220 \mathrm{~g}$ ) with an equal number of males and females were used in our research. All newly acquired rats were firstly housed in 10 cages by sex. The control (group 1, 30 rats), depressive model (group 2, 30 rats), and treatment (group 3 , 30 rats) groups were administered adaptive feeding for 7 days. Rats in group 1 were fed regularly, whereas rats in group 2 and 3 were were successively exposed to a variety of mild stressors, including tail suspension (1 $\mathrm{min})$, stroboscopic light (120 shoots/min), noise $(4 \mathrm{~h})$, swimming in ice water $(1 \mathrm{~h})$ or hot water $\left(45^{\circ} \mathrm{C}, 1 \mathrm{~h}\right)$, electrical stimulation $(10 \mathrm{~Hz})$, immobilization, food and water deprivation ( $24 \mathrm{~h}$ ), for three days each for 15 days. Subsequently, groups 2 and 3 were treated (gavaged) with saline and Paxil (paroxetine) (Zhejing Jianfeng Pharmaceutical Factory, Jinhua, Zhejiang Province,
China) at $0.2 \mathrm{mg} / \mathrm{ml} / \mathrm{day}$, respectively, for 30 days. After anesthetization and dissection, the brain, liver and kidney of each rat were separated and stored at $-80^{\circ} \mathrm{C}$ until further experiments.

\section{Analysis of 5-HT concentrations using an enzyme-linked immunosorbent assay (ELISA)}

Concentrations of 5-HT in the whole brain, liver, and kidney tissues of healthy, depressive, and treated rats were determined using enzyme-linked immunosorbent assay(ELISA) with a Covalent Binding Surfaces Plate (Thermo Scientific, 436006). Four repeats were established for both total protein extracted from the tissues and standards. The standard curve was generated by measuring the absorbance of 5-HT (Sigma-Aldrich, 14927) solutions with final concentrations of $31.25 \mathrm{ng}, 62.5 \mathrm{ng}, 125 \mathrm{ng}, 250$ ng, 500 ng, and 1000 ng. Coating buffer (Sangon, E6610040010) was used as a diluent to immobilize the protein. Protein coating was performed at $4{ }^{\circ} \mathrm{C}$ overnight following three washs with phosphate buffer (PBS) for 5 min each ( $5 \mathrm{~min} \times 3$ ). Proteins were then blocked with skim milk for $1 \mathrm{~h}$ at $37^{\circ} \mathrm{C}$ following three washs by PBST(PBS with Tween-20) for 5 min each. The plates were washed with PBST three times for 
5 min each and then the primary anti-5-HT antibody (Abcam, AB6444) was added at a dilution of 1:1000, and incubated at $37^{\circ} \mathrm{C}$ for $1 \mathrm{~h}$. After 3 washes with PBST for $5 \mathrm{~min}$ each, the secondary antibody (goat anti-rabbit) was added at a 1:1000 dilution and incubated at $37^{\circ} \mathrm{C}$ for $1 \mathrm{~h}$. Finally, visualization was performe dusing 1-step Ultra TMB-ELISA Substrate Solution (Pierce, 34028). The absorbance of each well was measured at $450 \mathrm{~nm}$ by an iMark Microplate Reader (BioRad, 15594).

\section{Immunohistochemistry analysis of TPH1/2 expression}

Immunohistochemistry was performed to visualize and compare the distributions of TPH1/2 in healthy, depressive and treated rats. Anti-TPH1 (Thermo Fisher Scientific, PA1-777) and anti-TPH2 (Abcam, AB184505) antibodies were used in these three sets of experiments, to detect the target proteins in paraffin sections of the brain, liver and kidney. The thickness of each section was $4 \mu \mathrm{m}$ to obtain a clear view of the intact tissue. All sections were mounted on gelatinized glass slides and treated identically. The sections were initially deparaffinized with 3 rinses in xylene for 5 min each, and rehydrated with a descending ethanol gradient $(100 \%, 95 \%$ and $70 \%)$ for 3 min each. After 5 min $\times 2$ washes with distilled water, all sections were incubated in endogenous peroxidase blocking solution (3\% hydrogen peroxide) for $5 \mathrm{~min}$ at room temperature and rinsed with running water for $5 \mathrm{~min}$. Subsequently, the sections were blocked by incubating them with $2 \%$ bovine serum albumin (BSA) for $10 \mathrm{~min}$ and washed 3 times with PBS for $10 \mathrm{~min}$ each. Antigen retrieval was then performed in citrate buffer by microwaving the sections 6 times for 10 $\mathrm{s}$ each. After another wash with running water for $5 \mathrm{~min}$, the sections were incubated overnight at $4^{\circ} \mathrm{C}$ with the antibodies against TPH1 diluted 1:140 in PBS, and antibodies against TPH2 diluted 1:250 in PBS. The reaction was terminated by washing the sections 3 times with PBST for 10 min each. The signals from bound primary antibodies were amplified by incubating the sections with secondary antibodies (goat anti-rabbit for TPH1/2, both diluted 1:500) for 30 $\min$ at $37^{\circ} \mathrm{C}$. The reaction was terminated by washing the sections 3 times with PBST for 10 min each, the peroxidase label was visualized by incubating the sections with 3,3'-diaminobenzidine (DAB) solution (Solarbio, DA1010) for 2-10 min at room temperature. Paraffin sections were counter-stained with haematoxylin (KeyGEN, KGA223) for $3 \mathrm{~min}$ at room temperature following a rinse with running water for $5 \mathrm{~min}$. Finally, the specimens were washed with running water, dehydrated with an increasing gradient of ethanol, cleared in xylene, and mounted with neural balsam. Photographs of all stained sections were captured with a microscope (Olympus, CKX41).

\section{Western blotting analysis of TPH1/2 expression}

Western blotting was performed to detect the distributions of the TPH isoforms and to semiquantitatively analyze the levels of the target proteins in the healthy, depressive model and treated rats. Proteins were extracted using a Whole Cell Lysis Assay Kit (KeyGEN, KGP2100), and protein concentration was then measured with a Bradford assay. Fifty micrograms of total protein were loaded in each lane. After transferring the proteins to a polyvinylidene fluoride (PVDF) membrane with a voltage of $40 \mathrm{~V}$ for $3 \mathrm{~h}$ at $4^{\circ} \mathrm{C}$, the membrane was blocked with $5 \%$ skim milk at room temperature for $2 \mathrm{~h}$. The membrane was then incubated with primary antibodies against TPH1 (Thermo Fisher Scientific, PA1777) and TPH2 (Abcam, AB52954) at a final dilution of 1:500 overnight at $4{ }^{\circ} \mathrm{C}$. On the second day, the membrane was washed and incubated with the goat anti-rabbit antibody at room temperature for $2 \mathrm{~h}$. Visualization was performed by adding ECL Western Blotting Substrate (Thermo Pierce, 32209), and bands were observed on a fluorescent/chemiluminescent detector (Tanon, 4500).

\section{Analysis of the TPH1/2 mRNA levels using reverse transcription-polymerase chain reaction (RT-PCR)}

RT-PCR was performed to determine whether the TPH mRNA levels were directly proportional to TPH1/2 expression in the brains of the healthy,depressive model and treated rats. Total RNA was extracted from the brains using an RNeasy Plus Mini Kit (Qiagen, 74134). Reverse transcription was performed with a PrimeScript RT-PCR Kit (TaKaRa, DRR014A) using random 6 mers (random 6-base primer for the transcription of DNA into rRNA, mRNA or tRNA) as primers. The mRNA was then amplified with Recombinant Taq DNA Polymerase (TaKaRa, R001AM) using gene-specific primers for TPH1, TPH2 and 18S ribosomal RNA (18s rRNA; used as an internal reference and positive control for RT-PCR). The primer sequences and size of the target sequences for RT-PCR are listed in Table 1. TPH1 and TPH2 primers were designed using the Primer Premier 5 software and were designed to span across exons and introns to exclude potential DNA contamination. The PCR was initiated at $95^{\circ} \mathrm{C}$ for $5 \mathrm{~min}$, and the amplifications were performed with 38 cycles at $95^{\circ} \mathrm{C}$ for $30 \mathrm{~s}$ (denaturation), $60^{\circ} \mathrm{C}$ for $30 \mathrm{~s}$ (annealing), and $72^{\circ} \mathrm{C}$ for $1 \mathrm{~min}$ (extension), followed by an extra extension step at $72^{\circ} \mathrm{C}$ for $10 \mathrm{~min}$. The PCR products were then visualized with $1 \%$ agarose gels stained by Gold View (Solarbio, G8142) and viewed in a fluorescent/chemiluminescent detector (Tanon, 4500). 


\section{Methylation-specific polymerase chain reaction (MSP) analysis of methylation status of the TPH1/2 genes}

Methylation-specific PCR (MSP) was performed to investigate the methylation of the $T P H 1 / 2$ gene promoters within the $\mathrm{CpG}$ islands located at the $5^{\prime}$-terminal, which may inhibit the transcription of TPH1/2 in the healthy, depressive model and treated rats. Methylation-specific primers and non-methylation specific primers were designed by Sangon Biotech Company. Total DNA was extracted from the whole brain, liver and kidney of the healthy, depressive model and treated rats using a DNeasy Blood \& Tissue Kit (Qiagen, 69504), and the final elution was performed by adding $100 \mu \mathrm{l}$ of DNase-free water. A TIANquick Midi Purification Kit (Tiangen, DP204) was used to further purify the DNA. Finally, $30 \mu \mathrm{l}$ of the purified DNA product was obtained. DNA was sulfurated with a CpGenome Turbo Bisulfite Modification Kit (Merck, S7847). DNA was then amplified with Recombinant Taq DNA Polymerase (TaKaRa, R001AM) using methylationspecific primers and non-methylation specific primers. The primer sequences and size of the target sequences for PCR are listed in Table 2. PCR was initiated at $95^{\circ} \mathrm{C}$ for $5 \mathrm{~min}$, and amplifications were performed by 33 cycles at $95^{\circ} \mathrm{C}$ for $30 \mathrm{~s}$ (denaturation), $52.5^{\circ} \mathrm{C}$ for $30 \mathrm{~s}$ (annealing), and $72^{\circ} \mathrm{C}$ for $1 \mathrm{~min}$ (extension), followed by an extra extension at $72^{\circ} \mathrm{C}$ for $10 \mathrm{~min}$. The PCR products were then visualized with $1 \%$ agarose gels stained by Gold View (Solarbio, G8142) and semi-quantitatively analyzed using a fluorescent/chemiluminescent detector (Tanon, 4500).

\section{Statistical analysis}

Data are presented as mean \pm S.D. The statistical analysis was performed using Student's $t$ test (for two experimental groups). Significance was set at $P<0.05$. Statistical significance was determined using Student' st test and the $F$ test (SPSS 11.5 software for Windows, SPSS Inc., Chicago, IL, USA).

\section{CONCLUSIONS}

As shown in the present study, 1) the two isoforms of TPH have a different spatial distribution, with TPH1 expressed predominantly in the peripheral tissues and TPH 2 primarily localized in the central serotonergic neurons; 2) Tissues 5-HT concentrations and TPH1/2 expression were decreased in brain tissues in the rat model of depression; 3) Stress inhibited $\mathrm{TPH} 2$ expression in the depressive rats possibly due to an increase in the methylation of the $\mathrm{TPH} 2$ gene promoter in brain tissues. Our results confirmed that 5-HT and TPH1/2 dysfunction were associated with depression. Notably, the stress-mediated decrease in TPH1/2 expression was related to increased methylation of the $T P H 1 / 2$ gene promoters.

\section{Ethics statement availability of data and materials}

This study protocol and animal experiments were approved by the Hainan Medical College Institutional Committee.

\section{Consent to publish}

This study does not involve human participants. All the authors and the Institution consent to publication.

\section{Authors' contributions}

YC and HX generated the animal model and performed the ELISA, immunohistochemistry and Western blottinganalysis. HX performed the MSP experiments. MZ and KL participated in the RT-PCR analysis. BL and RL participated in the design of the study and performed the statistical analysis. ML and CC conceived the study, and participated in its design and coordination and helped draft the manuscript. All authors read and approved the final manuscript.

\section{ACKNOWLEDGMENTS}

This work was supported by grants from the Natural Science Foundation of Hainan Province (Nos. 811208, 813198, and 814293)

\section{COMPETING INTERESTS}

The authors have no competing interests to declare.

\section{REFERENCES}

1. Kendler KS, Neale MC, Kessler RC, Herth AC, Eaves LJ. The lifetime history of major depression in women: reliability of diagnosis and heritability. Arch Gen Psychiatry. 1993; 50: 863-870.

2. Wittchen HU, Knauper B, Kessler RC. Lifetime risk of depression. Br J Psychiatry Suppl. 1994; 165: 16-22.

3. Kawai M, Rosen CJ. Minireview: a skeleton in serotonin's closet? Endocrinology. 2010; 151: 4103-4108.

4. Fidalgo S, Ivanov DK, Wood SH. Serotonin: from top to bottom. Biogerontology. 2013;14: 21-45.

5. Lucki I. The spectrum of behaviors influenced by serotonin. Biol Psychiatry. 1998; 44: 151-162.

6. Nutt DJ. The role of dopamine and norepinephrine in depression and antidepressant treatment. J Clin Psychiatry. 2006; 67: 3-8.

7. Maletic V, Robinson M, Oakes T, Iyengar S, Ball SG, Russell J. Neurobiology of depression: an integrated view of key findings. Int J Clin Pract. 2007; 61: 2030-2040.

8. Perez-Caceres D, Ciudad-Roberts A, Rodrigo MT, Pubill D, Camins A, Camarasa J, Escubedo E, Pallas M. 
Depression-like behaviors is dependent on age in male SAMP8 mice. Biogerontology. 2013; 14: 165-176.

9. Lin SH, Lee LT, Yang YK. Serotonin and mental disorders: a concise review on molecular neuroimaging evidence. Clin Psychopharmacol Neurosci. 2014; 12: 196-202.

10. Stanley M, Mann JJ. Increased serotonin-2 binding sites in frontal cortex of suicide victims. Lancet. 1983; 1: 214-216.

11. Walther DJ, Bader M. A unique central tryptophan hydroxylase isoform. Biochem Pharmacol. 2003; 66:1673-1680.

12. Pelosi B, Pratelli M, Migliarini S, Pacini G, Pasqualetti M. Generation of a Tph2 conditional knockout mouse line for time- and tissue-specific depletion of brain serotonin. PLos One. 2015; 10:e136422.

13. Reiter RJ. Pineal melatonin: cell biology of its synthesis and of its physiological interactions. Endocr Rev. 1991; 12: 151-180.

14. Cote F, Thevenot E, Fligny C, Fromes Y, Darmon M, Ripoche MA. Disruption of the non-neuronal tph1 gene demonstrates the importance of peripheral serotonin in cardiac function. Proc Natl Acad Sci USA. 2003; 100: 13525-13530.

15. Berger M, Gary JA, Roth BL. The expanded biology of serotonin. Annu Rev Med. 2009; 60: 355-366.

16. Zill P, Buttner A, Eisenmenger W, Muller J, Moller HJ. Predominant expression of tryptophan hydroxylase 1 mRNA in the pituitary: a postmortem study in human brain. Neuroscience. 2009; 159: 1274-1282.

17. Ramoz N, Versini A, Gorwood P. Eating disorders: an overview of treatment responses and the potential impact of vulnerability gene and endophenotypes. Expert Opin Pharmacother. 2007; 8: 2029-2044.

18. Walther DJ, Peter JU, Bashammakh S, Hortnagl H, Vilts M, Fink H, Bader M. Synthesis of serotonin by a second tryptaphan hydroxylase isoform. Science. 2003; 299: 76.

19. Migliarini S, Pacini G, Pelosi B, Lunardi G, Pasqualetti M. Lack of brain serotonin affects postnatal development and serotonergic neuronal circuitry formation. Mol Psychiatry. 2013; 18: 1106-1118.

20. Patel PD, Pontrello C, Burke S. Robust and tissue-specific expression of TPH2 versus TPH1 in rat raphe and pineal gland. Biol Psychiatry. 2004; 55: 428-433.

21. Gutknecht I, Kriegebaum C, Waider J, Schmitt A, Lesch KP. Spatio-temporal expression of tryptophan hydroxylase isoforms in murine and human brain: Convergent data from Tph2 knockout mice. Eur Neuropsychopharmacol. 2009; 19: 266-282.

22. Tzvetkov MV, Brockmöller J, Roots I, Kirchheiner J. Common genetic variations in human brain-specific tryptophan hydroxylase-2 and response to antidepressant treatment. Pharmacogenet Genomics. 2008; 18:495-506.
23. Veenstra-VanderWeele J, Anderson GM, Cook EH. Pharmacogenetics and the serotonin system: initial studies and future directions. Eur J Pharmacol. 2000; 410: 165-181.

24. Agrango V, Huang YY, Underwood MD, Mann JJ. Genetics of the serotonergic system in suicidal behavior. J Psychiatr Res. 2003; 37: 375-386.

25. Serretti A, Artioli P. From molecular biology to pharmacogenetics: a review of the literature on antidepressant treatment and suggestions of possible candidate genes. Psychopharmacology. 2004; 174: 490-503.

26. Sharp T. Neuroscience-a new molecule to brighten the mood. Science. 2006; 311: 45-46.

27. Lin SH, Lee LT, Yang YK. Serotonin and mental disorders: a concise review on molecular neuroimaging evidence. Clin Psychopharmacol Neurosci. 2014; 12: 196-202.

28. Benjamin DS, Jason RN, Marc GC. Brain 5-HT deficiency increases stress vulnerability and impairs antidepressant responses following psychosocial stress. Proc Natl Acad Sci USA. 2015; 112: 2557-2562.

29. Altar CA, Carhart J, Allen JD, Hall-Flavin D, Winner J, Dechairo B. Clinical utility of combinatorial pharmacogenomics-guided antidepressant therapy: evidence from three clinical studies. Mol Neuropsychiatry. 2015; 1:145-155.

30. El Marroun H, White TJ, Fernandez G, Jaddoe VW, Verhulst FC, Stricker BH, Tiemeier H. Prenatal exposure to selective serotonin reuptake inhibitors and non-verbal cognitive functioning in childhood. J Psychopharmacol. 2017; 31:346-355.

31. Safer DJ. Raising the minimum effective dose of serotonin reuptake inhibitor antidepressants: Adverse drug events. J Clin Psychopharmacol. 2016; 36:483-491.

32. Cui YH, Zheng Y. A meta-analysis on the efficacy and safety of St John's wort extract in depression therapy in comparison with selective serotonin reuptake inhibitors in adults. Neuropsychiatr Dis Treat. 2016;12:1715-1723.

33. Davis BA, Nagarajan A, Forrest LR, Singh SK. Mechanism of Paroxetine (Paxil) inhibition of the serotonin transporter. Sci Rep. 2016; 6:23789.

34. Hieronymus F, Nilsson S, Eriksson E. A mega-analysis of fixed-dose trials reveals dose-dependency and a rapid onset of action for the antidepressant effect of three selective serotonin reuptake inhibitors. Transl Psychiatry. 2016; 6:e834.

35. Szyf M. Epigenetics, DNA methylation and chromatin modifying drugs. Annu Rev Pharmacol Toxicol. 2009; 49: 243-263.

36. Holliday R. DNA methylation and epigenetic inheritance. Philos Trans R Soc Lond B Biol Sci. 1990; 326: 329-338.

37. Yang XJ, Seto E. HATs and HDACs: from structure, function and regulation to novel strategies for therapy and prevention. Oncogene. 2007; 26: 5310-5318. 